\title{
Proceeding
}

8th INSHS International Christmas Sport Scientific Conference, 5-7 December 2013. International Network of Sport and Health

Science. Szombathely, Hungary

\section{Effect of exercise with elastic cord on postural stability in a group of elite gymnasts}

\author{
IVAN STRUHÁR , LENKA DOVRTĚLOVÁ, KATEŘINA KAPOUNKOVÁ \\ Faculty of Sport Studies, Department of Health Support, Masaryk University, Czech Republic
}

\begin{abstract}
Struhár, l., Dovrtělová, L. \& Kapounková, K. (2014). Effect of exercise with elastic cord on postural stability in a group of elite gymnasts. J. Hum. Sport Exerc., 9(Proc1), pp.S495-S503. The main aim of this study was to find out if exercise with elastic cord improved postural stability in a group of elite gymnasts. For measuring postural stability an electronic balancing board with variable radius and integrated feedback was used. The exercise regimen was undertaken twice a week for 12 weeks. All participants were measured at the beginning of our study and then after 12 weeks. Participants had to stand on the electronic balance board during 30 seconds with open eyes and kept the board balanced using feedback from the screen. After that we compared the results of each participant. The results were expressed by number from 0 to 100. Twenty-nine elite gymnasts volunteered for this study. Participants did not report any neuromusculoskeletal injuries or other diseases that may affect balance performance. Before participating in the study, all parents of gymnasts read and signed the informed consent form. The participants were assigned to a control group (15 girls; mean age $=13.78 \pm 1.62$ years; mean height $=1.57 \pm 0.09 \mathrm{~m}$; mean mass $=46.16 \pm 8.71 \mathrm{~kg}$ ) and experimental group (14 girls; mean age $=14.1 \pm 2.0$ years; mean height $=1.56 \pm 0.08 \mathrm{~m}$; mean mass $=45.6 \pm 10.55 \mathrm{~kg}$ ). The total number of time spending in training was 18 hours per week. Experimental group performed 2 hours plus of exercise with elastic cord. One of the aims of our study was to decide if we can observe differences between beginning and final measurements in experimental group. We used $t$-test for paired samples ( $p=0.006578$; the significance level $95 \%)$. Therefore we can indicate our training programme with elastic cord as a way of improving postural stability in our group of elite gymnasts. Key words: BALANCE TRAINING, BALANCE BOARD, SPINAL STABILIZATION.
\end{abstract}

Corresponding author. Faculty of Sport Studies, Department of Health Support, Masaryk University, Czech Republic E-mail: struhar@mail.muni.cz 8th INSHS International Christmas Sport Scientific Conference, 5-7 December 2013. International Network of Sport and Health Science. Szombathely, Hungary.

JOURNAL OF HUMAN SPORT \& EXERCISE ISSN 1988-5202

(c) Faculty of Education. University of Alicante

doi:10.14198/jhse.2014.9.Proc1.38

VOLUME 9 | Proc1 | 2014 | S495 


\section{INTRODUCTION}

Maintaining of postural control is an essential part in both elite sport and sport for all. Proper maintenance of balance and postural equilibrium is therefore a vital component in sport and sport compensation (Riemann \& Guskiewicz, 2000). The loss of postural control can be considered as a risk factor of injury. It was proved the association between measures of postural stability and improved range of movement in order to prevention of falls (Nitz \& Choy, 2004). Postural control is always changing and can be improved through balance training not only in childhood but adulthood and retirement as well (Gruber et al., 2007). There are many factors which can influence the level of postural stability. Balance training can have a positive effect on sensory system. The question is how we can summarize exercises with the aim of improving stability and balance. It is not only balance training or postural stability training. Several terms can be found which may be considered as a way of improving stability such as sensomotoric training, neuromuscular training or proprioreceptive training.

The postural control system utilizes complex processes involving both sensory and motor components. Maintaining of postural equilibrium requires sensorimotor information within the central nervous system and execution of appropriate musculoskeletal response (Riemann \& Guskiewicz, 2000). The musculoskeletal core includes the abdominal structures, spine, hips, pelvis and the lower limbs (Kibler et al., 2006). Then, lumbo-pelvic muscles provide a stable platform in order to control movements (Willson et al., 2005).

The selected exercises were based on dynamic stabilization and coordination (it was chosen SM System). It is type of exercise with elastic cord which combines complex training of the locomotory apparatus. The cord provides movement which activate muscle closed chains against slow resistance. Spiral muscle chains provide a force of traction and the traction is used for the treatment of functional spinal disorders but it can also be used as an optimisation of movement during physical activity. It is also important to perform exercises slowly and to slow down at the end of the movement with elastic cord. The resistance of the elastic cord can be adjusted but we should exercise with a force which can be handled (Smíšek, Smíšková, \& Smišková, 2009).

\section{MATERIAL AND METHODS}

\section{Participants}

Twenty-nine elite gymnasts volunteered for this study. Participants did not report any neuromusculoskeletal injuries, serious joint disorders, impaired vision or other diseases that may affect balance performance. Participants had not experience with postural stability programme or other form of core stability programme during their gymnastics training or physical education class. If participant was involved in equivalent type of training programme, we had to exclude subject from our study. Participant (only in experimental group) was also excluded from the study if the attendance was less than $90 \%$ of total time in intervention programme. All participants had been training for 18 hours per week at the time of experiment. The participants were randomly assigned to a control group ( 15 girls; mean age $=13.78 \pm 1.62$ years; mean height $=1.57 \pm 0.09 \mathrm{~m}$; mean mass $=46.16 \pm 8.71 \mathrm{~kg}$ ) and experimental group (14 girls; mean age $=14.1 \pm 2.0$ years; mean height $=1.56 \pm 0.08 \mathrm{~m}$; mean mass $=45.6 \pm 10.55 \mathrm{~kg}$ ). The total number of time spending in training was 18 hours per week. Experimental group performed 2 hours plus of exercise with elastic cord. The total number of time spending in training was 18 hours per week. 


\section{Measures}

The main task of participants was to maintain a balance in medio-lateral position. For measuring postural stability was used electronic balancing board with variable radius and integrated feedback. After measuring, each performance of participant was expressed by number from 0 to 100 . A score of 100 is considered as the worst case and zero score is the best. The overall score was created as a weighted average of several parameters. The parameters include the whole area covered within the profile, area outside the profile, recovery time and extra time taken. The tilting part was set with radius of $5 \mathrm{~cm}$ for the experiment. It was chosen the situation on the electronic balance board when the participant tries to keep the balance with using feedback from the screen (Figure 1).

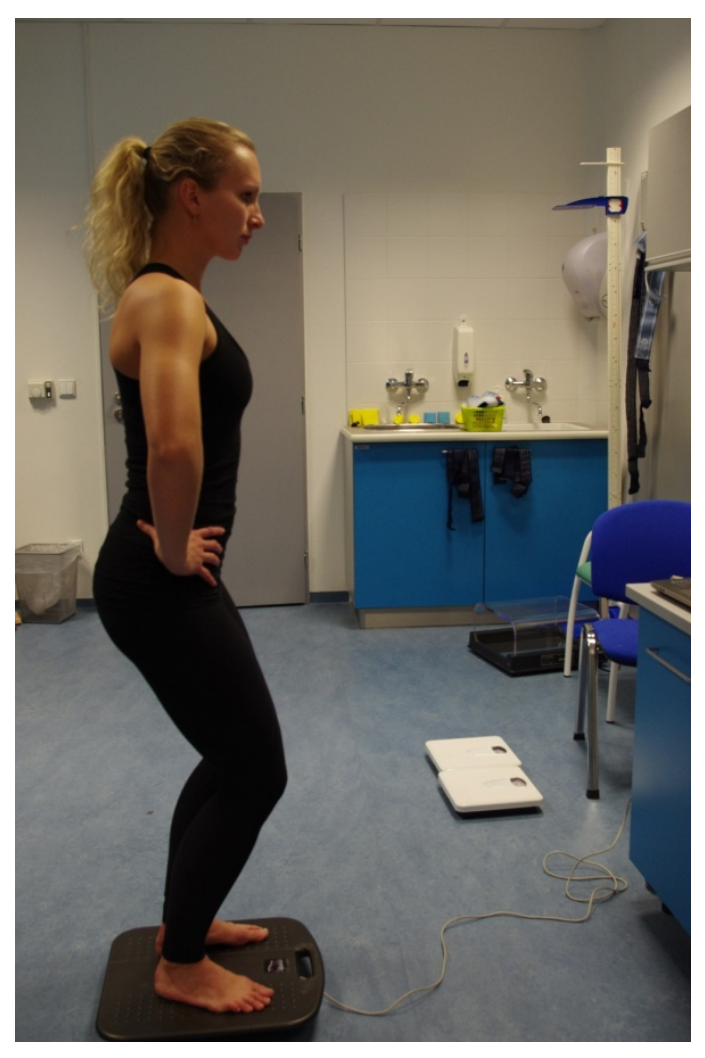

Figure 1. The position on the electronic balance board using feedback

The gymnastics training warm-up was completed before the testing. Participants were advised not to consume any sort of medication, 24 hours prior of the measurement. All participants were measured before the intervention balance exercise and after 3 months. At the beginning of measuring, the electronic balance board was tilted to the right. Each participant had to stand barefoot on the electronic balance board for 30 seconds. During the measuring, it was not allowed to speak. The position of the feet on the electronic balance board was also controlled. The participant had to stand barefoot with bent knees and the feet were open at a $30^{\circ}$ angle (Figure 2 ). 


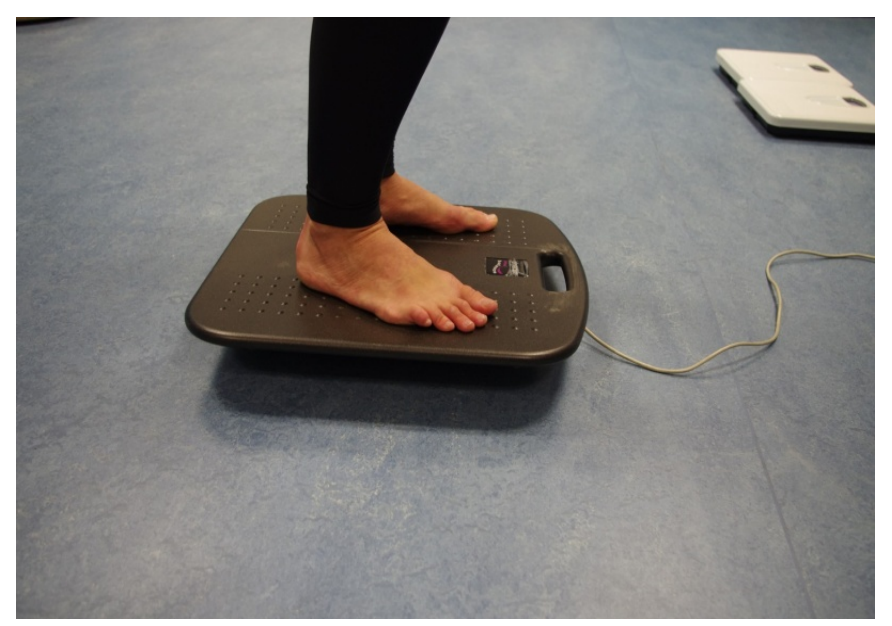

Figure 2. Positioning of feet on the board

The heels were $5 \mathrm{~cm}$ apart. It was allowed to have hands on the hips. It was secured a protection the participant in case of a fall. Each participant got visual feedback from the screen. Before the testing, the participants had the opportunity to try position on the electronic balance board.

\section{Procedures}

At the beginning of the study, a baseline measurement of postural stability was conducted as a pre-test. The postural stability programme and the correct muscle contraction were explained and demonstrated by physical therapist for experimental group (every intervention lesson was under the supervision of the postural stability programme designer). The correctness of the exercise was controlled during the intervention programme. The physical therapist focused on the activity of abdominal muscles and inhibition of paravertebral muscles. The postural stability programme with elastic cord for experimental group lasted 3 months (in addition to their normal training). The control group was without any form of postural stability programme for 3 months. All participants were measured after 3 months. The postural stability training programme lasted an hour during gymnastic training, two times a week for 3 months. The design of the study was set up that the first six weeks were exercised without a special balance mat and then from 6th week to the end of the experiment was used balance mat for every exercise (Figure 3). The participants were also challenged with more and more difficult tasks.

Before the experiment, all participants and their parents read and signed an informed consent form. The postural stability programme always started after warm-up exercises. In total, the postural stability programme featured 5 exercises that focused on dynamic stabilization and coordination. At the end of postural stability programme, participants stretched their muscles which were used during the workout. Exercise 3 was performed on one leg to improve sense of balance and increase spiral stabilization (the participant repeats the same for the other side).

\section{Exercise protocol}

Exercise 1: Participant stands relaxed, the palm of the exercising hand facing down. The shoulder blade is extended forward. Then, participant tight the buttocks and pull the shoulder blade back and down. The hand is completely relaxed and remains extended by the elastic rope, the palm rotates upwards. When participant is in this position, she lifts the heel from the floor. After that, the participant repeats the same for the other side. Participants perform 3 sets of 12 repetitions. 
Exercise 2: Participant stands relaxed backwards. Firstly, participant raises the arm back with pushing the elbows and palms as far back as possible. Then, participant raises the arm as far as it goes and looks down. The chin is tucked toward the breastbone and the limb is raised. After this, the chest is slowly bent towards the pelvis but the arm is in the same position. The arm completes very slowly the circle. After that, the participant repeats the same for the other side. Participants perform 4 sets of 10 repetitions.

Exercise 3: Participant stands relaxed and chest is bent downwards. The arms are crossed in front of the body. The shoulder blades have to be pressed backward and downward. Then, participant tries to pull the shoulder blades together, backward and downward as much as possible. The palms rotate upwards and the head is raised. When the spine is aligned, participant raises the limb from the floor and tries to remain in this position 10 seconds. After that, the participant repeats the same for the other side. Participants perform 4 sets of 10 repetitions.

Exercise 4: Participant stands relaxed, the right knee is raised upwards, and the left hand touches the knee. Then, participant moves the right foot backwards and tip of the foot touches the floor at the end of movement. The head has to be extending upwards and shoulders are pressed down. It is highly important to emphasize that when the knees pass each other, participant has to tight the left buttock. At the end of the exercise, the right buttock is tightened and the left one must remain tightened. After that, the participant repeats the exercise with the other limb. Participants perform 3 sets of 12 repetitions.

Exercise 5: Participant kneels on back leg and the front leg is extended forward. The buttocks are tightened, the chest and head are levelled into the posterior axis. Then, participant starts to roll down vertebra by vertebra. The chest is pulled towards the stretched leg. Participant remains in this position for 10 seconds and then he/she aligns the chest vertebra by vertebra to the starting position. Participants perform 4 sets of 12 repetitions (Smíšek, Smíšková, \& Smišková, 2009).

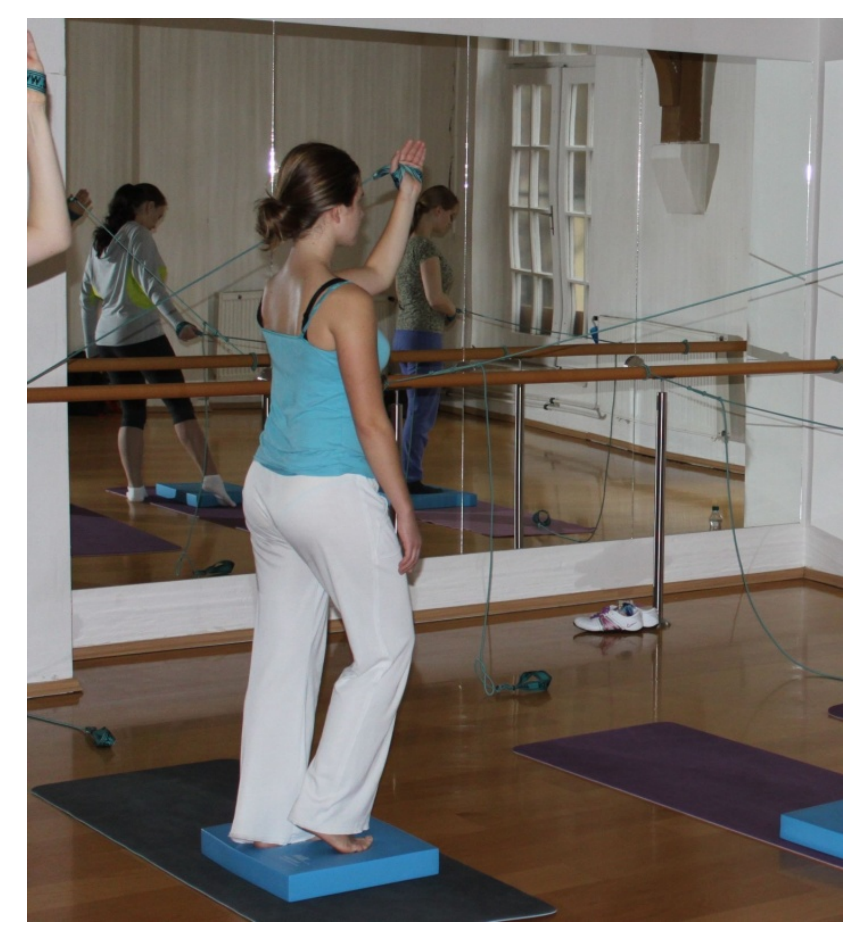

Figure 3. Exercising with special balance mat 
Analysis

Analyses were conducted using programme Statistica 12.0 and included descriptive statistics. Paired t-test was used to analyze the date within each group. Significance was set at $p<0.05$ and results are given as the mean $\pm S D$.

\section{RESULTS}

At the beginning of the study it was needed to find out if the control and experimental groups are homogenous. It was supposed all individuals can be regarded as the same type. That was the null hypothesis. The alternative hypothesis was contrary to the null hypothesis. The independent t-test was used in that case $(p=0.365944)$ and the null hypothesis was not rejected. One of the aims of the study was to decide if the differences between pre-test and post-test in experimental group will occur. The paired samples t-test was used ( $p=0.006578$; the significance level $95 \%)$. The intervention programme with elastic cord improved postural stability in a group of elite gymnasts.

Table 1. Descriptive statistic of participants

\begin{tabular}{lcccccc}
\hline \multirow{2}{*}{ Participant group } & \multicolumn{2}{c}{ Age (years) } & \multicolumn{2}{c}{ Height $(\mathrm{m})$} & \multicolumn{2}{c}{ Weight $(\mathrm{kg})$} \\
& Mean & SD & Mean & SD & Mean & SD \\
\hline Experimental $(\mathrm{n}=14)$ & 14-Jan & 2 & Jan-56 & 0.08 & 45.6 & Oct-55 \\
Control $(\mathrm{n}=15)$ & 13.78 & Jan-62 & Jan-57 & 0.09 & 46.16 & Aug-71 \\
& & & & & & \\
\hline
\end{tabular}

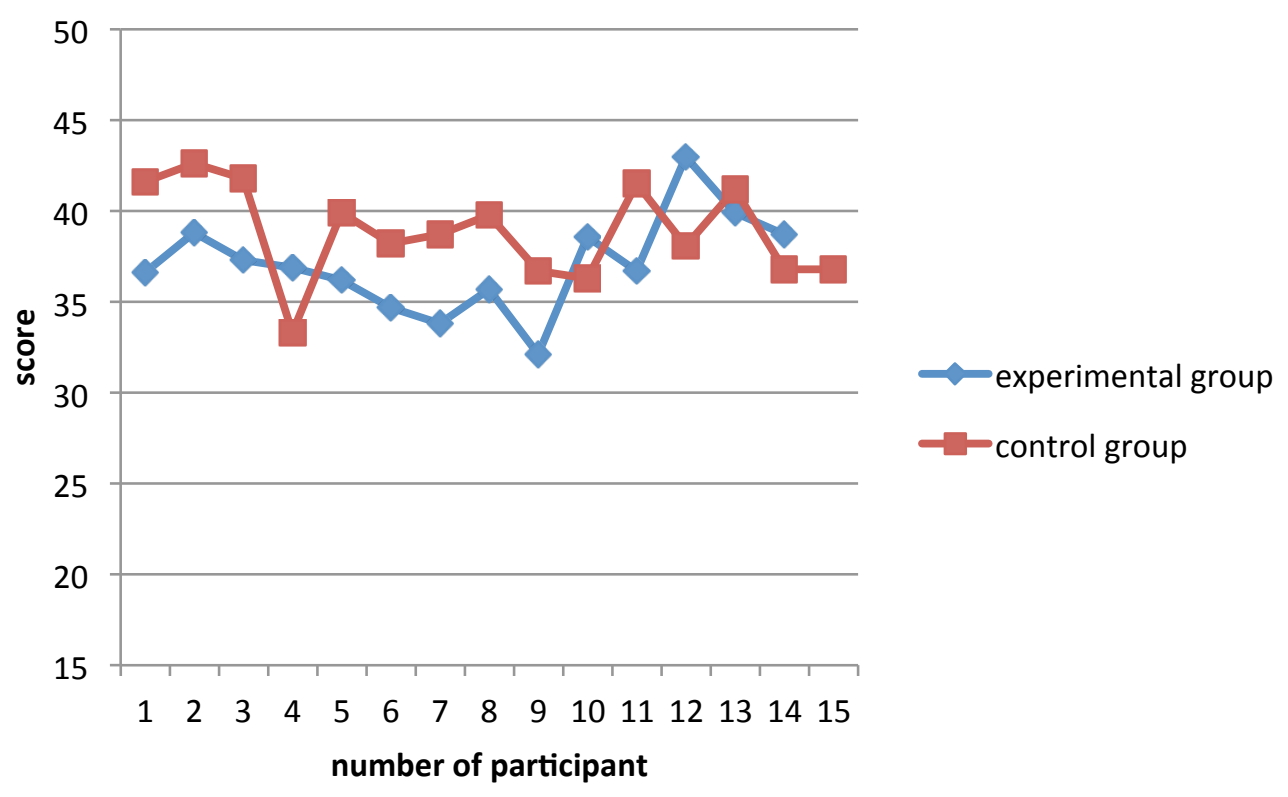

Figure 4. The score of participants in pre-test 
The effect of intervention programme on postural stability was measured using the electronic balance board where a score of 100 is considered as the worst case and zero score is the best.

A mean score of participants in experimental group had decreased (pre-test $37.07 \pm 2.70$; post-test $32.82 \pm 5.34$ ) which was significantly lower but mean score of participants in control group had risen (pretest 38.88 \pm 2.62 ; post-test $39.33 \pm 2.52$ ).

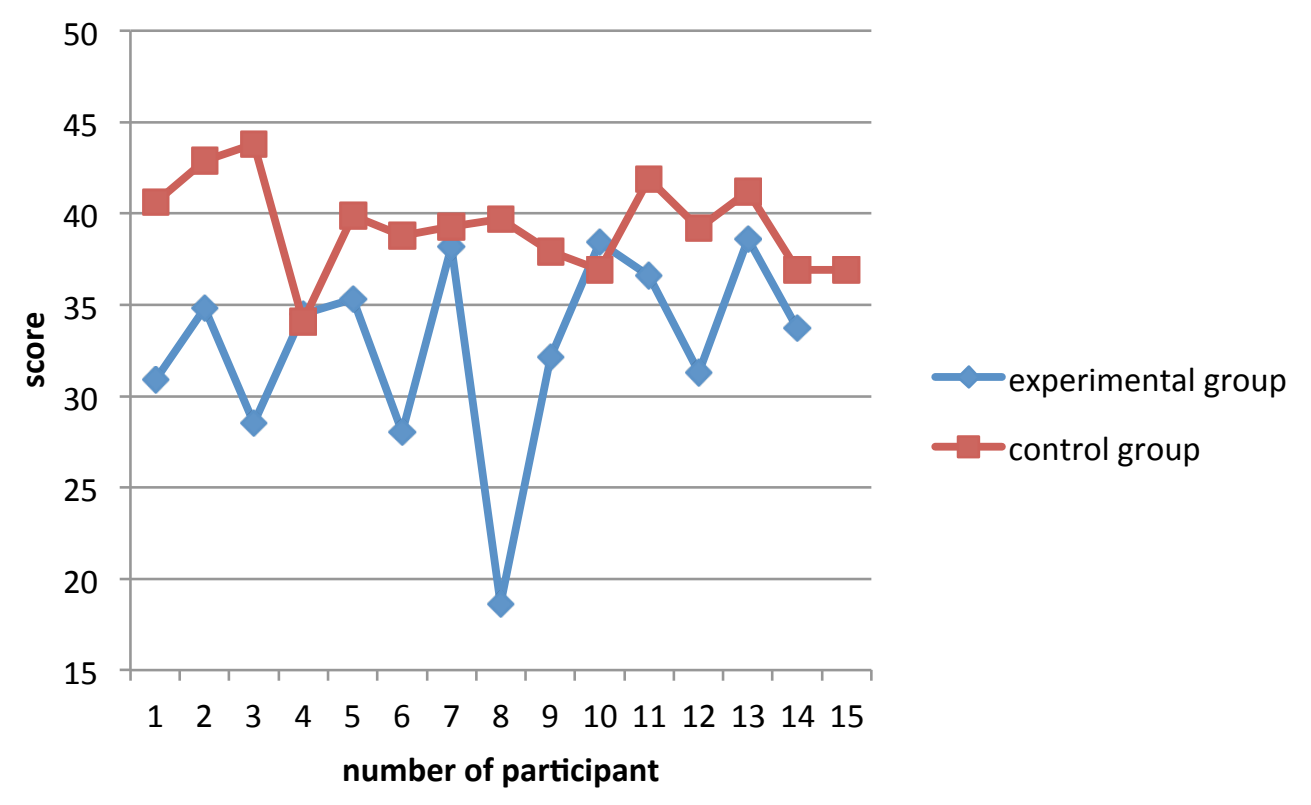

Figure 5. The score of participants in post-test

Table 2. The overall score of participants on the balance board

\begin{tabular}{lcc}
\hline Participant group & Pre-test & Post-test \\
\hline Experimental $(n=14)$ & $37.07 \pm 2.70$ & $32.82 \pm 5.34$ \\
Control $(n=15)$ & $38.88 \pm 2.62$ & $39.33 \pm 2.52$ \\
\hline
\end{tabular}

\section{DISCUSSION}

The purpose of the study was to examine the effect of postural stability training with elastic cord in a group of elite gymnasts. Postural stability was measured with using electronic balance board. We hypothesized that the intervention programme could improve postural stability after 3 months of intervention in experimental group. The results showed that mean score of participants in the experimental group after the intervention programme was significantly lower than mean score in the control group $(32.82 \pm 5.34$ vs. $39.33 \pm 2.52$ ). Various studies have confirmed the positive effect of stability training programme on improving postural stability (Carter et al, 2006; Bassett \& Leach, 2011; Yu \& Lee, 2012; Bliven \& Anderson, 2013; Abdi \& Sadeghi, 2013). 
Maintaining of standing position is essential in daily life. It is necessary to be able to perform many movements which are based on cognitive processing and postural control.

It was also found a relationship between postural stability and injuries (Witchalls et al., 2012). The core strength and stability is essential to ensure accurate movement of the limbs in gymnastics. The musculoskeletal core provides a link between upper and lower body. It plays a crucial role in sport performance but it is not only about having a strong core. This sign can be seen during the training when the young athletes are not able to stay balanced when it is needed. This situation is often connected with injury. The main aim of the present experiment was to prepare postural stability programme with elastic cord.

\section{CONCLUSIONS}

The results confirm the contribution of postural stability programme in the sport preparation of elite gymnasts. Postural stability training is beneficial not only for athletes but also for patients and adults. Impairments in postural control are often accompanied with risk of falling (Lord et al., 1992). We are convinced that future studies should be focused on anteroposterior balance stability, postural stability in standing on one leg with respect of dominant leg and gender differences in postural stability. The results showed that twice weekly participation in postural stability programme for 3 months period may improve postural stability.

\section{ACKNOWLEDGEMENT}

The work was supported by European operational program Education for Competitiveness Cz.1.07/2.4.00/17.0039, Creation of a Network of Professional Institutions Participating in the Fight against the Occurrence of Metabolic Syndrome.

\section{REFERENCES}

1. Abdi, J. \& Sadeghi, H. (2013). The effect of eight-week core stability training program on the dynamic balance in young elite footballers. Scoliosis (17487161), 8(Suppl 1), pp.20-21.

2. Bassett, S.H. \& Leach, L.L. (2011). The effect of an eight-week training programme on core stability in junior female elite gymnasts. African Journal for Physical, Health Education, Recreation \& Dance, pp.9-19.

3. Bliven, K.C.H. \& Anderson, B. E. (2013). Core Stability Training for Injury Prevention. Sports Health: A Multidisciplinary Approach, 5(6), pp.514-522.

4. Carter, J.M., Beam, W.C., McMahan, S.G., Barr, M.L. \& Brown, L.E. (2006). The Effects of Stability Ball Training on Spinal Stability in Sedentary Individuals. J Strength Cond Res (Allen Press Publishing Services Inc.), 20(2), pp.429-435.

5. Gruber, M., Gruber, S.B.H., Taube, W., Schubert, M., Beck, S.C. \& Gollhofer, A. (2007). Differential effects of ballistic versus sensorimotor training on rate of force development and neural activation in humans. J Strength Cond Res, 21(1), pp.274-282.

6. Kibler, W.B., Press, J. \& Sciascia, A. (2006). The role of core stability in athletic function. Sports Med (Auckland, N.Z.), 36(3), pp.189-198.

7. Kuczyński, M., Szymańska, M. \& Bieć, E. (2011). Dual-task effect on postural control in high-level competitive dancers. J Sport Sci, 29(5), pp.539-545. 
8. Lord, S.R., McLean, D. \& Stathers, G. (1992). Physiological Factors Associated with Injurious Falls in Older People Living in the Community. Gerontology, 38(6), pp.338-346.

9. Nitz, J.C. \& Choy, N.L. (2004). The efficacy of a specific balance-strategy training programme for preventing falls among older people: a pilot randomised controlled trial. Age and Ageing, 33(1), pp.52-58.

10. Riemann, B.L. \& Guskiewicz, K.M. (2000). Contribution of peripheral somatosensory system to balance and postural equilibrium. In Scott M. Lephart \&, Freddie H. Fu (Eds.), Proprioception and Neuromuscular Control in Joint Stability (pp.37-51.). Champaign, IL: Human Kinetics

11. Willson, J.D., Dougherty, C.P., Ireland, M.L. \& Davis, I.M. (2005). Core stability and its relationship to lower extremity function and injury. The Journal of the American Academy of Orthopaedic Surgeons, 13(5), pp.316-325.

12. Witchalls, J., Blanch, P., Waddington, G. \& Adams, R. (2012). Intrinsic functional deficits associated with increased risk of ankle injuries: a systematic review with meta-analysis. Brit J Sport Med, 46(7), pp.515-523.

13. Yu, J.H. \& Lee, G.C. (2012). Effect of core stability training using pilates on lower extremity muscle strength and postural stability in healthy subjects. Isokinetics \& Exercise Science, 20(2), pp.141146. 